\title{
Activation of Rho Family GTPases by Small Molecules
}

Charuta C. Palsuledesai, ${ }^{\S, \|, \nabla \odot ~ Z u r a b ~ S u r v i l a d z e, ~}{ }^{\S, \dagger, \nabla, \square}$ Anna Waller, ${ }^{\S, \dagger}$ T. Fabiola Miscioscia, ${ }^{\ddagger, \#, \nabla, \bigcirc}$ Yuna Guo, $\$, \|, \triangle$ Yang Wu, ${ }^{\dagger, \triangle}$ Jake Strouse, ${ }^{\dagger,}$ Elsa Romero, ${ }^{\S, \|}$ Virginia M. Salas, ${ }^{\dagger, \nabla}$ Ramona Curpan, ${ }^{\ddagger}, \perp$ Susan Young, ${ }^{\dagger,}$ Mark Carter, ${ }^{\dagger, \square}$ Terry Foutz, ${ }^{\dagger, \diamond}$ Zhanna Galochkina, $^{\S}$ Harold Ames, ${ }^{\dagger}$ Mark K. Haynes, ${ }^{\S, \dagger}$ Bruce S. Edwards, ${ }^{\S, \|, \dagger, \square}$ Orazio Nicolotti, ${ }^{\#}$ Li Luo, ${ }^{\S, @ ~ O l e g ~ U r s u, ~}{ }^{\ddagger}$ Cristian G. Bologa, Tudor I. Oprea, ${ }^{\S, \$}$ Angela Wandinger-Ness, ${ }^{,},, \|, \bullet$ and Larry A. Sklar ${ }^{\S, \|, \dagger, \bullet}$

${ }^{\dagger}$ Center for Molecular Discovery, ${ }^{\ddagger}$ Translational Informatics Division, Department of Internal Medicine, ${ }^{\S}$ Comprehensive Cancer Center, and "Department of Pathology, University of New Mexico School of Medicine, Albuquerque, New Mexico 87131, United States

${ }^{\perp}$ Institute of Chemistry, Romanian Academy, Timisoara, Romania

\#Dipartimento di Farmacia-Scienze del Farmaco, Università di Bari “Aldo Moro”, Via Orabona, 4, 70126 Bari, Italy

${ }^{\circledR}$ Division of Epidemiology, Department of Internal Medicine, University of New Mexico School of Medicine, Albuquerque, New Mexico 87131, United States

\section{Supporting Information}

ABSTRACT: Ras and Ras-related small GTPases are key regulators of diverse cellular functions that impact cell growth, survival, motility, morphogenesis, and differentiation. They are important targets for studies of disease mechanisms as well as drug discovery. Here, we report the characterization of small molecule agonists of one or more of six Rho, Rab, and Ras family GTPases that were first identified through flow cytometry-based, multiplexed high-throughput screening of 200000 compounds. The activators were categorized into three distinct chemical families that are represented by three lead

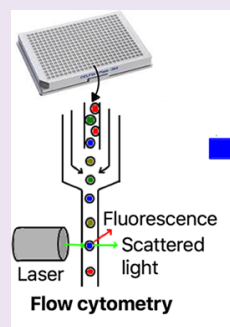

High throughput screening (HTS)

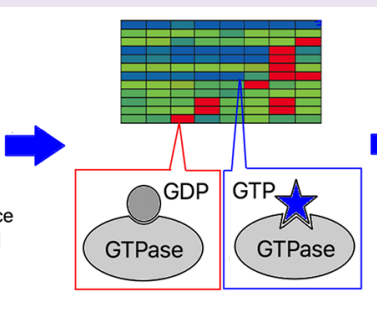

Secondary dose response assays

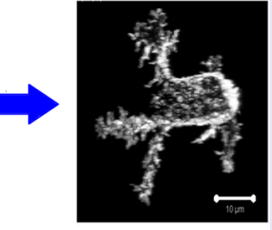

GTPase activation in cell-based assays compounds having the highest activity. Virtual screening predicted additional compounds with potential GTPase activating properties. Secondary dose-response assays performed on compounds identified through these screens confirmed agonist activity of 43 compounds. While the lead and second most active small molecules acted as pan activators of multiple GTPase subfamilies, others showed partial selectivity for Ras and Rab proteins. The compounds did not stimulate nucleotide exchange by guanine nucleotide exchange factors and did not protect against GAP-stimulated GTP hydrolysis. The activating properties were caused by a reversible stabilization of the GTP-bound state and prolonged effector protein interactions. Notably, these compounds were active both in vitro and in cell-based assays, and small molecule-mediated changes in Rho GTPase activities were directly coupled to measurable changes in cytoskeletal rearrangements that dictate cell morphology.

$\mathrm{R}$ as and Ras-related small GTPases are key regulators of diverse cellular functions that impact cell growth, survival, motility, morphogenesis, and differentiation. ${ }^{1,2}$ Even while GTPases have been recognized as important targets of disease and intervention, there have been limited systematic efforts to identify small molecules that target GTPases. ${ }^{3}$ GTPases toggle between GTP-bound active and GDP-bound inactive forms under the control of specific regulatory proteins that control the catalytic cycle. ${ }^{2,4}$ Guanine nucleotide exchange factors (GEFs) facilitate exchange of GDP for GTP, causing GTPase activation. On the other hand, GTPase-activating proteins (GAPs) promote GTPase activity (hydrolysis of bound GTP to GDP), leading to inactivation of small GTPases. ${ }^{2}$ In the GTPbound active form, small GTPases interact with effector proteins to implement downstream signaling. ${ }^{5}$ The GTPase catalytic cycle and effector protein interactions offer nodes for small molecule intervention for which there are examples of efficacy for select GTPases. ${ }^{6-10}$ To the best of our knowledge, however, all known small molecules act as antagonists.

Ras superfamily members contribute to oncogenesis, hereditary disorders, and infectious diseases when mutated or hyperactivated. ${ }^{11,12}$ Mutant or hyperactivated Ras subfamily members are implicated in $30 \%$ of all human cancers because of their roles in cell signaling and are particularly prevalent in myeloid leukemia and pancreatic, lung, and colon carcinomas. ${ }^{4,13-15}$ Cancer cell proliferation, motility, and invasiveness have been linked to cytoskeletal rearrangements caused by increased levels of activation of Rho GTPases through

Received: January 16, 2018

Accepted: May 10, 2018

Published: May 10, 2018 
a.

\section{CID888706}

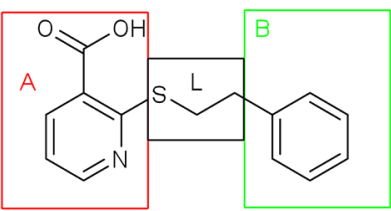

2-phenethylsulfanylpyridine3-carboxylic acid b.

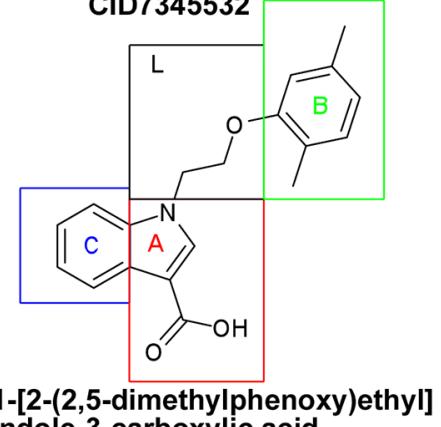

c.

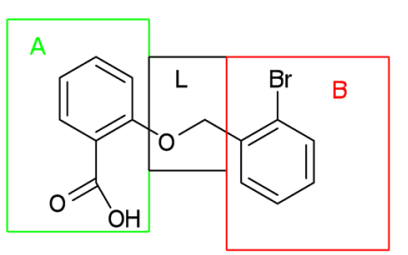

2-[(2-bromophenyl)methoxy]

Figure 1. Structures of lead compounds from three chemical families of GTPase activators. HTS and virtual screening identify three families of small molecule GTPase activators, having the general structure section A-linker L-section B (outlined by boxes). The lead compounds representing the (a) nicotinic acid, (b) indole acid, and (c) salicylic acid analogue families are depicted.

overexpression or mutations in their regulatory GEFs- or GAPs. ${ }^{5,16-18}$ Altered expression or mutation of Rab proteins and/or their effectors underlies human diseases such as cancers, neuronal dysfunction, retinal degeneration, kidney disease, and immune and pigmentation disorders, based on their functions in endocytic membrane transport. ${ }^{19-22}$ While hyperactivated GTPases are considered attractive therapeutic targets, few clinical applications have been realized in humans, and Ras has only recently seen resurgence as a "druggable target".,23-25

Loss of function or diminished GTPase activity is also associated with human diseases but has not yet been therapeutically considered. For example, a dominant negative missense mutation in Rac2 was found to interfere with both Rac1 and Rac2 function and cause impaired resistance to infection, while reduced $\mathrm{Cdc} 42$ activity has been found to be associated with Fanconi anemia. ${ }^{26,27}$ Missense mutations in Rab GTPases or associated regulatory proteins are associated with immune dysfunction, pigmentation, or neurological disorders due to impaired GTPase function and/or functional insufficiency. ${ }^{12,20,28}$ Thus, Ras and Ras-related GTPases are important targets for the development of small molecule agonists to complement known antagonists. Such agonists will aid studies of disease mechanism and serve as scaffolds for future therapeutics.

Genetic tools such as ectopic expression of wild type or mutant proteins, RNA interference, and CRISPR have enabled studies of Ras superfamily GTPase roles in molecular and cellular biology of diseases. ${ }^{29-32}$ However, these methods suffer from some disadvantages. Generating knockout cellular and animal models removes all the functions of the deleted gene, ${ }^{33}$ is laborious, and may be lethal to the living systems. ${ }^{34}$ Importantly, cells can also adapt to the genetic manipulations through compensatory responses. ${ }^{34,35}$ Small molecule compounds can provide a rapid way to study the acute effects of activation or inactivation of target proteins. Such pharmacological agonists and antagonists often work reversibly enabling a washout experiment to reverse the effect. ${ }^{36}$ While there are challenges to obtaining small molecule probes with the desired specificity, they provide excellent opportunities for measuring initial responses and for performing dose-response studies, as well as for testing impacts of perturbing only one of the functions of a multifunctional protein. ${ }^{33}$ Recent reports describe methods for spatiotemporally controlling GTPase activation by chemically inducing a GTPase activator protein. ${ }^{37,38}$ However, these methods require individual design of an inducible system for each target GTPase and extensive genetic engineering.

We previously systematically screened a library of approximately 200000 small molecules using flow cytometry-based high-throughput screening (HTS) to identify three chemical families of small molecule activators (agonists, or compounds that increase levels of GTP-bound GTPases) of Ras superfamily GTPases. ${ }^{39}$ Virtual screening of a ChemDiv library identified additional compounds predicted to have GTPase activating properties. Here, compounds having the highest activities in confirmatory secondary dose-response assays are extensively characterized and found to increase the activities of Rho family GTPases in both in vitro and cellular assays. While this work presents indirect proof of binding of the small molecule activators to GTPases, microscale thermophoresis data indicate direct binding.

\section{RESULTS AND DISCUSSION}

Identification of Three Chemical Families of GTPase Activators. Sensitive and quantitative detection of an increase or decrease in fluorescence intensities with a high dynamic range makes the flow cytometry-based platform particularly advantageous for the screening of molecular libraries. ${ }^{40}$ The application of this HyperCyt technology-based HTS enabled identification of activators of GTP binding by Ras and Rasrelated GTPases (Figure S1). ${ }^{39}$ In this work, we have used the term "GTPase activator (or agonist)" to describe compounds causing an increase in the GTP-bound active forms of GTPases. An increased level of GTPase activation in the presence of a small molecule activator refers to an increase in GTP-bound GTPase levels, rather than an increase in GTPase enzyme (GTP hydrolysis) activity.

We screened a library of approximately 200000 small molecules from the Molecular Libraries Small Molecule Repository (MLSMR) for their activities against six small GTPases (Cdc42, Rab2, Rab7, activated Rac1Q61L, Rac1, and H-Ras) and reported on the composite results. ${ }^{39}$ Special glutathione $(\mathrm{GSH})$ bead sets having varied red fluorescence intensities at a fixed wavelength were used for multiplexing the screening process. Inhibitors as well as activators of GTPases were identified by measuring the effects of small molecules on the binding of a fluorescent GTP to individual GST-GTPase chimeras. The assays were performed in the presence of EDTA because it chelates $\mathrm{Mg}^{2+}$ and increases the nucleotide off rate, thereby facilitating nucleotide exchange. In total, 1877 hits were identified in this primary screen consisting of 165 compounds 
a.
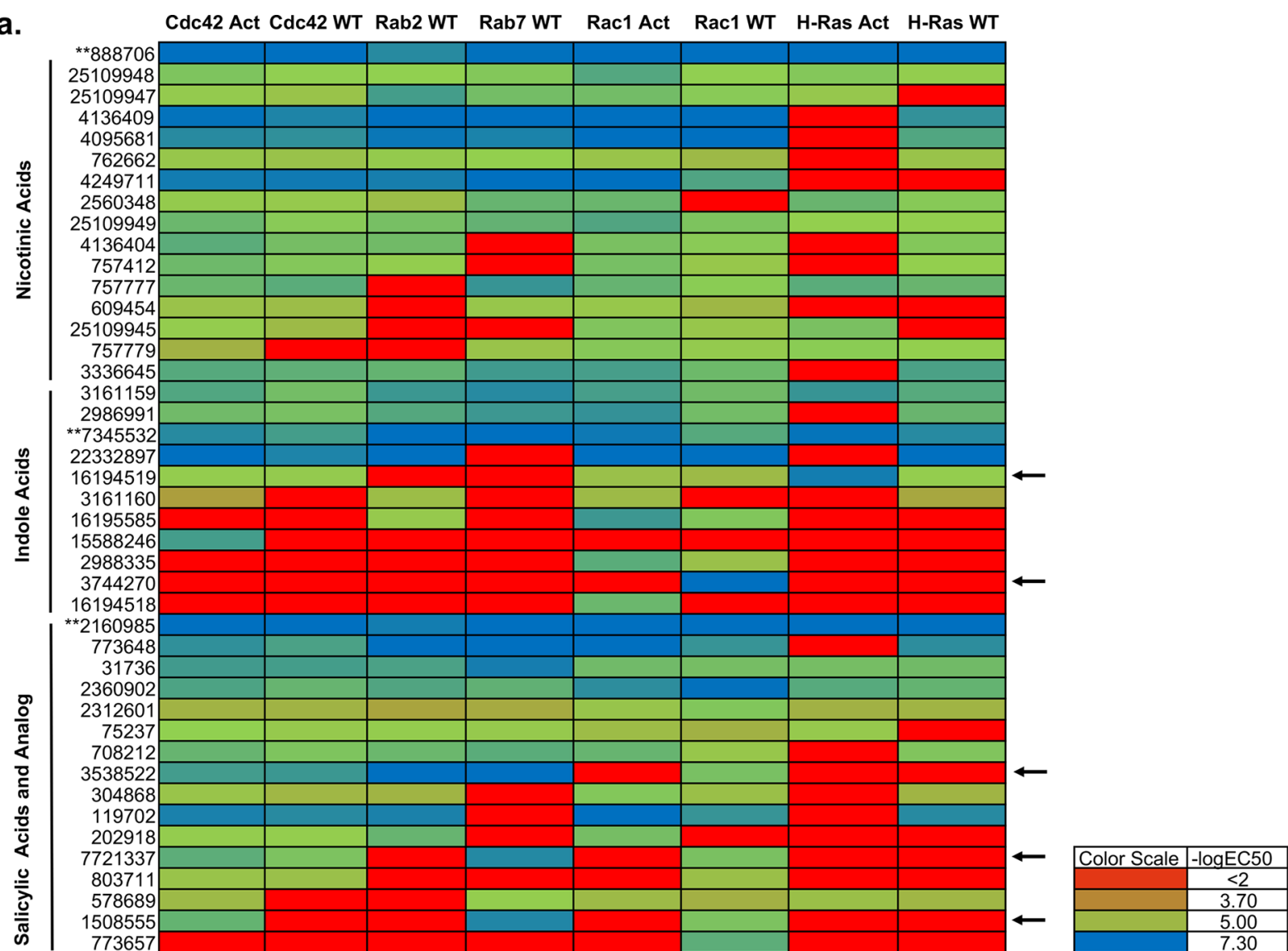

b.

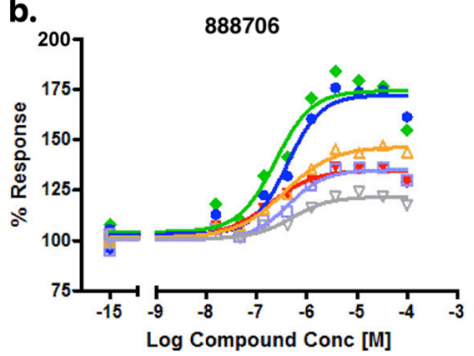

c.

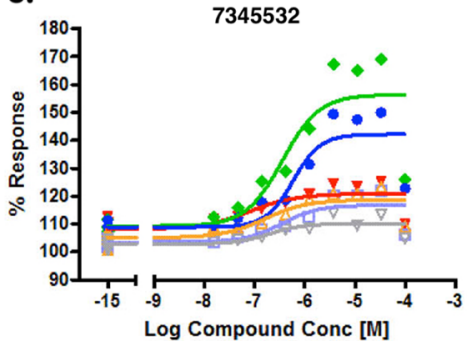

d.

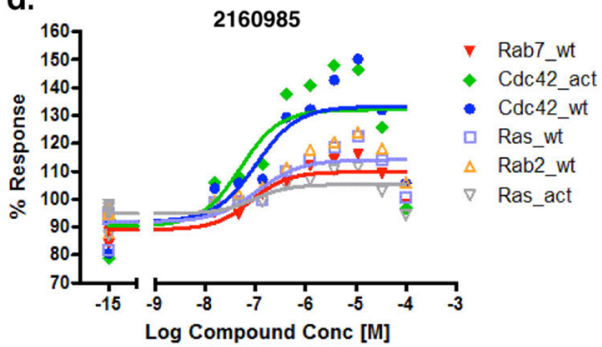

Figure 2. Heat map and dose-response curves showing small molecule agonists active against GTPase targets. (a) Activity $\left(-\log\right.$ EC $\left._{50}\right)$ heat map of 43 compounds, representing three families (nicotinic acids, indole acids, and carboxylic acids), that activate GTP binding on the eight indicated GTPases. Blue reflects the best biological activity measured as increased in vitro nucleotide binding activity, whereas red reflects a lack of activity. CID numbers of compounds tested in dose-response assays are given (modified from Probe Report ${ }^{39}$ ). CID numbers with asterisks indicate lead compounds from each of the three chemical families, and arrows indicate compounds with GTPase-selective activity. (b-d) Representative doseresponse assays of the three lead compounds on six indicated GTPase targets. Assays were performed in the presence of $100 \mathrm{nM}$ BODIPY-GTP and EDTA and varying concentrations of small molecule activators using proteins bound to red fluorescent glutathione beads of differing intensities. wt indicates wild type GTPase, and act indicates activated mutant GTPase. Mutants include H-RasG12V, Rac1Q61L, and Cdc42Q61L.

identified as activators and 573 compounds as inhibitors of one or more of six GTPases screened. On the order of 100-500 compounds were found to be active per GTPase target, enabling a comprehensive evaluation of small molecules active against various Ras-related GTPase family members. Results of this screen are summarized in the open access Pubchem database as required for projects conducted under the Roadmap Initiative (AID 757-761, 764). ${ }^{39}$ Data from one 384-well plate with a single activator [compound identification number (CID) 888706] of 320 test compounds on the plate are represented in Figure S1. Here, we selectively characterize the GTPase activators chemically and through biochemical and cell-based assays.
The most active agonists $\left(\log \mathrm{EC}_{50}>6\right)$ had the general structure section $\mathrm{A}$-linker $\mathrm{L}-$ section $\mathrm{B}$ and were clustered into three chemical families: nicotinic acids, indole acids, and salicylic acids (Figure $1 \mathrm{a}-\mathrm{c}$ and Tables S1-S4). Analyses of the chemical core structures revealed that section A was confined to one of three aromatic rings: phenyl, pyridine, or indole with a carboxylic acid group directly bound to the aromatic ring. The linker was, in general, an aliphatic chain that was one to four atoms in length and frequently contained one or two heteroatoms (sulfur, nitrogen, and oxygen) or, in some cases, carbonyl, amidic, or ester groups. A phenyl ring was present in section $\mathrm{B}$ in most cases. The aromatic ring in section $\mathrm{B}$ was often unsubstituted, or substituted in the ortho, meta, or para 
a.

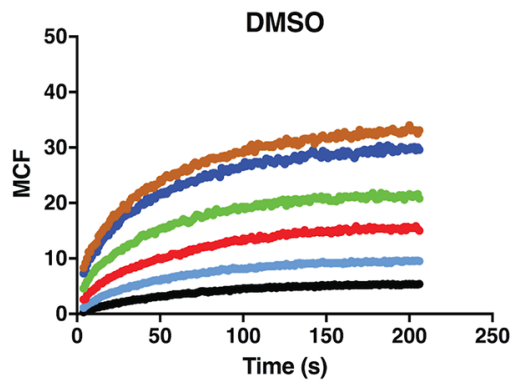

c.

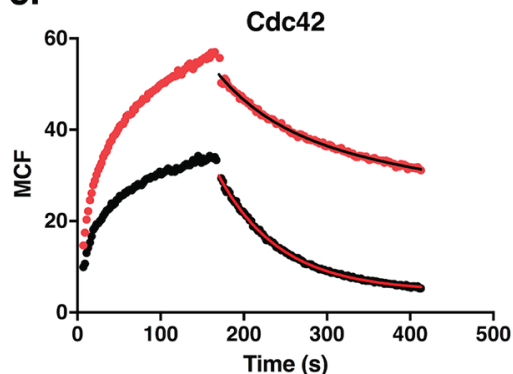

e.

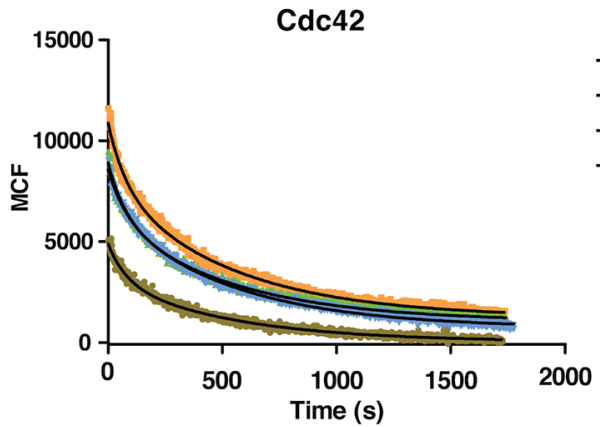

b.

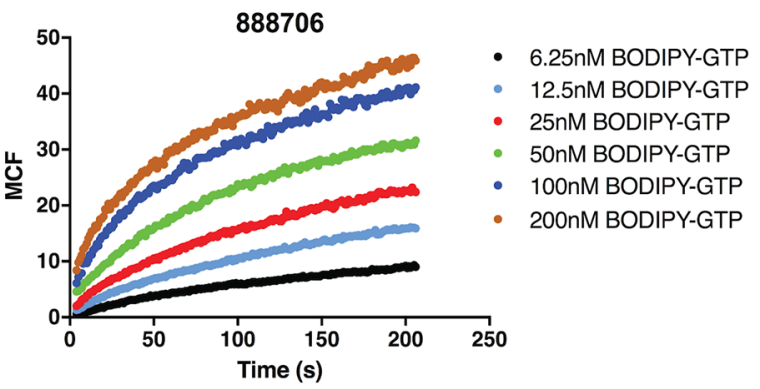

d.

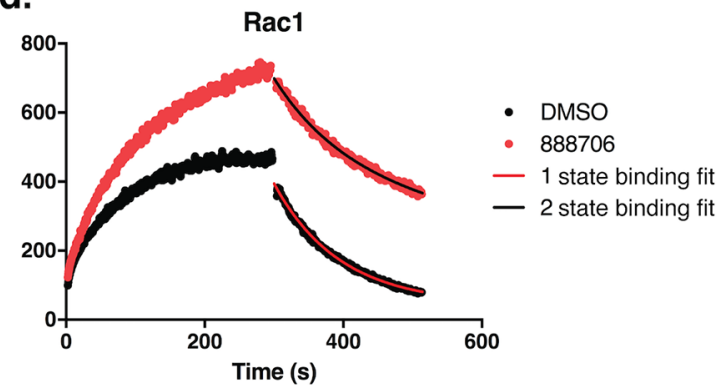

Figure 3. Small molecule activators increase nucleotide binding affinity, resulting in additional bound GTP over time and slowed dissociation of GTP. ( $\mathrm{a}$ and b) Cdc42-conjugated beads were preincubated for 3 min with $1 \%$ DMSO and $10 \mu \mathrm{M}$ activator 888706, respectively. Association binding of indicated concentrations of BODIPY-GTP to the Cdc42-conjugated beads was measured by following the fluorescence on the beads as a function of time. Cdc42-conjugated (c) and Racl-conjugated (d) beads were preincubated with DMSO or $10 \mu \mathrm{M}$ activator 888706 . The fluorescence on the beads was measured as a function of time following the addition of $200 \mathrm{nM}$ BODIPY-GTP. Dissociation of BODIPY-GTP was initiated via addition of GTP $(200 \mu \mathrm{M}$ final concentration) at $170 \mathrm{~s}$ (c) or $300 \mathrm{~s}(\mathrm{~d})$. Plotted are mean channel fluorescence (MCF) values vs time in seconds, with the measured data as dots and lines for the calculated fits by one-state (DMSO) or two-state (with activator) binding models (see the text for details) $(n=2)$. Note that because of instrument setting differences, MCF values for Racl-conjugated beads were higher. (e) Dissociation of BODIPY-GTP from Cdc42-conjugated beads was monitored after preincubation with $10 \mu \mathrm{M}$ activator 888706 and $200 \mathrm{nM}$ BODIPY-GTP binding for the indicated times. Plotted are MCF values vs time after the addition of $200 \mu \mathrm{M}$ GTP.

positions in general with halogens, alkyl, methoxy groups, carbonyl, or nitro groups. Three lead compounds (CIDs 888706,7345532 , and 2160985), representative of three chemical families, were selected on the basis of their high measured activity and their three distinct scaffold structures (Tables S1-S4).

Because molecules having similar shapes and physicochemical properties may exhibit similar bioactivity on a particular target, ${ }^{41,42}$ the three lead compounds were used as queries in a virtual screen to identify other potential GTPase activators. A chemical library of 20509 compounds with a carboxylic acid group from ChemDiv was submitted to virtual screening using ROCS, resulting in the identification of 914 molecules after removal of duplicates and previously screened compounds. The virtual hit list was narrowed to 99 molecules by selecting those that were more structurally similar to activators identified in the HTS. Shape overlays of lead compounds from all three series demonstrate good overlap among these structures, which further suggests that these compounds can bind through similar modes to the GTPase targets (Figure S9).

Secondary Dose-Response Assays Confirm Agonist Activities. Secondary dose-response assays were performed on a total of 1281 unique compounds, which included both activator and inhibitor hits from HTS and the predicted activators from ChemDiv screening, to confirm activity and determine potency. Along with six GTPases used in the primary HTS, these compounds were additionally tested against activating H-RasG12V and Cdc42Q61L mutants in a flow cytometry-based dose-response assay performed in EDTAcontaining buffer. A total of 215 hits were obtained with an average confirmation rate of $6.5 \%$, with 77 compounds acting as inhibitors (data not shown) and 43 acting as activators of GTP binding (Table S1). Of these 43 activators, 22 were identified from the HTS and 21 were identified by virtual screening. $\mathrm{EC}_{50}$ values of these compounds were in the range of $10 \mathrm{nM}$ to 100 $\mu \mathrm{M}$ for individual members of the Ras superfamily of GTPases 


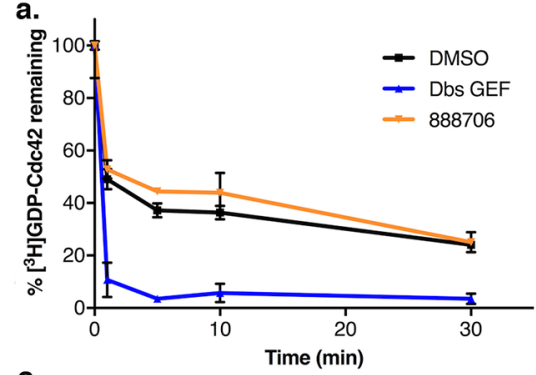

c.

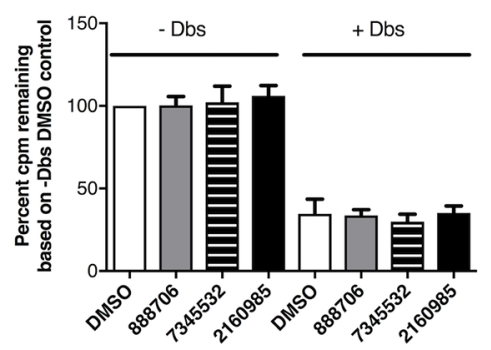

e.

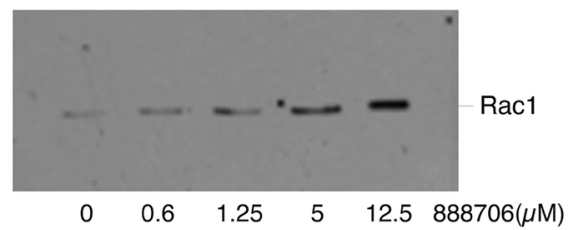

b.

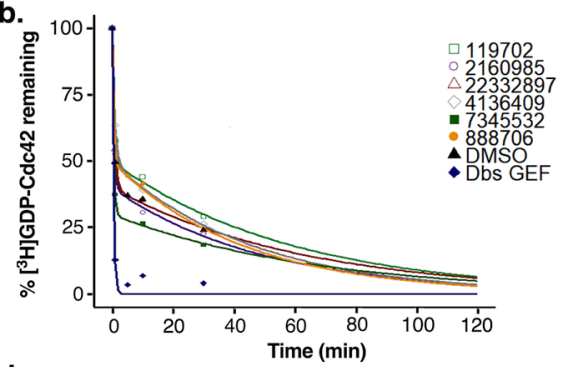

d.
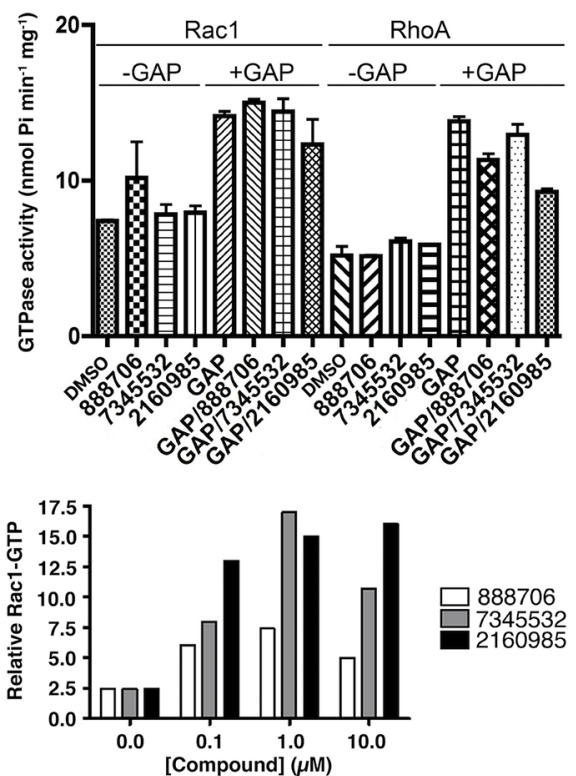

Figure 4. Small molecule activators enhance effector protein binding but do not perturb GEF or GAP activities. (a and b) Dbs RhoGEF assay monitoring release of bound $\left[{ }^{3} \mathrm{H}\right] \mathrm{GDP}$ from purified $\mathrm{Cdc} 42$ as detailed in Methods. Panel a shows the percentage of initial $\left[{ }^{3} \mathrm{H}\right] \mathrm{GDP}$ remaining bound to Cdc42 $(\sim 0.04 \mathrm{nM})$ (average of $3950 \pm 475 \mathrm{cpm} /$ sample at $\left.t_{0}\right)$ as a function of time after addition of excess unlabeled GTP in the presence of $200 \mathrm{nM}$ Rho Dbs GEF alone, DMSO, or small molecule activators $(n=3)$. Panel $\mathrm{b}$ shows the best fit for GDP dissociation following additions of the Dbs GEF or activator compound determined using two-phase exponential decay $\left(Y=P_{1} \mathrm{e}^{-K_{1} t}+P_{2} \mathrm{e}^{-K_{2} t}\right.$, where $\left.P_{1}+P_{2}=100\right)$. Panel c shows $\left[{ }^{3} \mathrm{H}\right]$ GDP remaining bound to Cdc42 $(\sim 0.04 \mathrm{nM}) 20 \mathrm{~min}$ after addition of excess unlabeled GTP to samples, in the presence of the indicated activator and in the absence $(-)$ or presence $(+)$ of $200 \mathrm{nM}$ Rho Dbs GEF. Samples treated with only DMSO served as negative controls $(n=2)$. (d) Purified Racl or Rho GTPases $(17.8 \mu \mathrm{M})$ were incubated for $15 \mathrm{~min}$ in the presence of small molecule activators and $200 \mu \mathrm{M}$ GTP prior to the addition of purified RhoGAP $(5.5 \mu \mathrm{M})$. GTP hydrolysis was measured at $650 \mathrm{~nm}$ based on colorimetric detection of phosphate release after 20 min $(n=2)$. (e) PAK effector binding was used to measure Racl activation status. Purified His-Rac1 ( $80 \mathrm{ng}$ ) was briefly preincubated with compounds $(0-12.5 \mu \mathrm{M}) ; 125 \mathrm{nM}$ GTP $\gamma$ S was added, and active Racl was isolated by binding to $5 \mu \mathrm{g}$ GST-PAK-PBD immobilized on GSH beads. Bound active Racl was detected by immunoblotting. The top panel shows a representative immunoblot (previously shown in Figure $3 \mathrm{~A}$ of Probe Report ${ }^{39}$ ), and the bottom panel shows quantification of dose-dependent activation for three compounds $(n=1)$.

(Figure 2a). While all three lead compounds (designated by asterisks) were high-affinity pan activators (Figure $2 b-d$ ), other members of the SAR series have some GTPase selectivity (e.g., CID 16194519 on activated H-RasG12V, CID 3744270 on Rac1wt, CID 3538522 on Rab2 and Rab7, and CIDs 7721337 and 1508555 on Rab7), denoted by arrows (Figure 2a).

Rho Family GTPase Activation by Small Molecule Activators. To characterize the effects of the identified activators on GTPase-GTP binding, we measured the kinetics of binding of BODIPY-GTP to Rac1 and Cdc42 in the presence of DMSO or one of the lead activator compounds, 888706. Kinetic binding measurements with Cdc42-conjugated beads in the presence of $1 \%$ DMSO resulted in concentrationdependent binding of BODIPY-GTP that plateaued and reached equilibrium after $\sim 200 \mathrm{~s}$ (Figure 3a). In contrast, the addition of $10 \mu \mathrm{M}$ activator increased binding activity of BODIPY-GTP above DMSO levels with a continued upward trajectory beyond $200 \mathrm{~s}$ (Figure $3 \mathrm{~b}$ ).
Because the approach to equilibrium is governed by the off rate, dissociation binding assays were performed with beads conjugated to Cdc42 or Racl. Excess nonfluorescent GTP was added to initiate dissociation of bound BODIPY-GTP. Rapid dissociation was observed for both GTPases in the DMSO controls (Figure 3c,d). Fitting the dissociation data by nonlinear regression to a one-state binding model yielded off rates of 0.013 and $0.010 \mathrm{~s}^{-1}$ for Cdc42 and Racl, respectively. Dissociation of fluorescent GTP in the presence of the activator commenced at a higher occupancy (more bound GTP), was slower, and did not fit a one-state binding model when applied over the same time frames as the DMSO controls. Therefore, dissociation of BODIPY-GTP from Cdc42-conjugated beads was studied over longer times to explore the possibility of heterogeneous BODIPY-GTP binding in the presence of the activator. Cdc42-conjugated beads were preincubated with 10 $\mu \mathrm{M} 888706$; BODIPY-GTP was allowed to associate for 10$120 \mathrm{~min}$, and then dissociation kinetics of BODIPY-GTP were 
measured (Figure 3e). One-state fits gave a systematic error (Figure S2). Statistical comparisons between the one-state and two-state fits in GraphPad Prism using the extra sum-of-squares $F$ test with a $P$ value of $<0.05$ established the two-state fit as the preferred model (Figure S2). In a "global" analysis, in which all dissociation curves were fit with the same rates, two components were identified: a slow off rate state (higher nucleotide affinity) and a fast off rate state (lower nucleotide affinity). After BODIPY-GTP binding for $10 \mathrm{~min}, \sim 64 \%$ slow state $\left(0.0019 \mathrm{~s}^{-1}\right)$ and $36 \%$ fast state $\left(0.013 \mathrm{~s}^{-1}\right)$ were estimated. The fast component tended to decrease with longer BODIPY-GTP association times (i.e., after binding of BODIPY-GTP for $120 \mathrm{~min}$, only $26 \%$ fast state was present). The half-time for interconversion between fast and slow states was estimated to be $\sim 5 \mathrm{~h}$. On the basis of these observations, the dissociation data in the presence of activator in panels $\mathrm{c}$ and $\mathrm{d}$ of Figure 3 were fit using nonlinear regression to a two-state binding model. This fitting included the constraints that one state was fit with equivalent off rates calculated from the DMSO controls, which at $0.013 \mathrm{~s}^{-1}$ for $\mathrm{Cdc} 42$ was the same in both experiments (Figure 3c,e), with the baseline plateau being the same as DMSO controls. The resulting off rates calculated from the proposed biphasic dissociation in the presence of activator over minutes in panels $c$ and $d$ of Figure 3 are entirely consistent with the evolution of the off rates over hours in Figure 3e. One possible explanation for binding heterogeneity is a slow concerted (rather than independent) binding of the nucleotide and activator in which interconvertible states depend upon initial conditions (mixture of nucleotide-bound and apo states, divalent cation binding, and, conformational flexibility of the protein).

We performed further equilibrium binding studies to characterize two representative activators from each chemical family. We selected the compounds with the highest stimulatory activities in the dose-response assays, optimal solubility ( $\log S=-4.5$ to -3.5 ) and membrane permeability $(\log P<5)$ (Table S1). We varied the concentration of the fluorescent GTP across the $K_{\mathrm{d}}$ range and measured the new apparent $K_{\mathrm{d}}$ and apparent $B_{\max }$ values using two different concentrations of each activator $(1$ and $10 \mu \mathrm{M}$ ) (Figure S3 shows equilibrium binding to Rab7). Assays performed in the presence of $1 \%$ DMSO served as the control, and unconjugated glutathione "scavenger" beads were included as a sink to capture any free GST-GTPases released from the bead sets during the assay and to avoid scrambling of the bead sets. As shown graphically in Figure S4a and numerically in Table S1, the apparent $K_{\mathrm{d}}$ decreased by 1.2-3.1-fold. The effect was most pronounced for the Rho family GTPase Cdc42 and minimal for Rab and Ras GTPases. It is important to note that the biphasic dissociation rates give rise to apparent $K_{\mathrm{d}}$ values that reflect the heterogeneity of two dissociation rates and the percentages of different affinity states present. Thus, even at high activator concentrations, the $K_{\mathrm{d}}$ does not vary in proportion to the ratio of the two dissociation rates. The apparent $B_{\max }$ which represents the maximal fluorescent nucleotide binding, increased 1.2-1.8-fold in the presence of all activators relative to the DMSO control (Table S1 and Figure S4b). A general assessment of the complex guanine nucleotide binding is that the presence of the activator results in the GTPase exhibiting greater affinity for the guanine nucleotide. A change in magnesium coordination was suggested by docking studies in the presence of allosteric carboxylate inhibitors. ${ }^{43}$ We speculate that the activators may stabilize GTP binding through a similar $\mathrm{Mg}^{2+}$-mediated mechanism.

Small Molecule Activators Have No Effect on GEF or GAP Activities. The lead compounds are pan GTPase activators and exhibited a robust activation of Rho family GTPases. Therefore, the remainder of the analyses were focused on Rho family GTPases. In vivo, all GTPases depend on GEFs for conversion to the GTP-bound state and on GTPase-activating proteins (GAPs) for inactivation through stimulated GTP hydrolysis. To test the possibility that the compounds might serve as activators through a GEF-like mechanism, we measured the in vitro nucleotide exchange of purified Cdc42 in the presence of the compounds, as compared to nucleotide exchange mediated by the RhoGEF catalytic Dbs domain. The addition of the Dbs GEF significantly stimulated the release of $\left[{ }^{3} \mathrm{H}\right] \mathrm{GDP}$ from $\mathrm{Cdc} 42$, and basal levels of $\mathrm{Cdc} 42-\left[{ }^{3} \mathrm{H}\right]$ GDP were attained in $<2 \mathrm{~min}$ (Figure $4 \mathrm{a}$ ). On the other hand, exchange of $\left[{ }^{3} \mathrm{H}\right] \mathrm{GDP}$ on $\mathrm{Cdc} 42$ upon addition of activating compound 888706 resembled the negative DMSO control (Figure 4a). For all the activator compounds tested, near-complete nucleotide exchange took much longer (100$137 \mathrm{~min})$ than Dbs GEF-catalyzed exchange did (1.5 min) (Figure $4 \mathrm{~b}$ and Figure S5). Furthermore, the small molecule activators did not alter GEF-mediated nucleotide exchange, as seen in Figure 4c. This suggests that the molecules act as activators by stabilizing the GTP-bound form rather than by enhancing GDP dissociation and stabilizing the nucleotide-free form as GEF proteins do. ${ }^{44}$ We then tested if the activating properties of the compounds could be attributed to inhibition of GTP hydrolysis. Colorimetric phosphate release assays demonstrated that GAP-dependent and GAP-independent GTP hydrolysis rates of Racl and RhoA were not affected in the presence of the activator compounds (Figure $4 \mathrm{~d}$ ).

The effects of activator compounds on GTPase-effector interactions were measured by taking advantage of the exquisite selectivity with which effector proteins bind to only the GTPbound, active GTPases. ${ }^{2,5}$ GTP-bound Racl and Cdc42 interact with a common effector, the serine/threonine $\mathrm{p}-21$ activated kinase (PAK), via the highly conserved Cdc42/Rac interactive binding (PBD or CRIB) motif of PAK. ${ }^{45}$ Purified GST-tagged PAK-PBD immobilized on glutathione beads was used to pull down and quantify the fraction of Racl in the active form (GTP-bound) in response to incubation with the three lead compounds in each family. His-Racl was incubated with increasing concentrations of each compound (0-12.5 $\mu \mathrm{M})$ in the presence of GTP- $\gamma$-S to prevent nucleotide hydrolysis and changes in effector binding during the assay. The fraction of active His-Racl was detected using immunoblot analyses. Quantification of the immunoblots showed a dosedependent increase in the level of Racl activation in the presence of increasing amounts of each compound (Figure 4e). Thus, the small molecule activators increase the fraction of GTPase in the active conformation, which can be quantified by effector protein interaction. The compounds are predicted to bind to an allosteric site, resulting in increased nucleotide affinity observed experimentally as a decreased $K_{d}$ and stabilization of the active conformation. Taken together, the data suggest that the compound binding site is likely distinct from both the GEF and GAP binding sites, but binding results in stabilization of the activated, GTP-bound state possibly through a pocket adjacent to the nucleotide. ${ }^{43}$

Small Molecule Activators Increase the Size of the Pool of Active GTP-Bound Rac in Cell-Based Assays. 
Previously, we found that R-naproxen, which was detected as a Racl and Cdc42 activator in the primary HTS screen, was in fact an inhibitor of Rac1 and Cdc42 in a cellular setting. ${ }^{43}$ These findings clearly demonstrate that it is critical to assess activities of compounds identified through HTS in cell-based assays to establish whether they act as agonists or antagonists under physiological conditions and in a cellular context.

We assessed the activity of the lead compounds in cells by testing the changes in the pool of active GTPases in the presence and absence of the compounds. Having predicted log $S$ and $\log P$ values of all three lead activators that were consistent with aqueous solubility and membrane permeability, we anticipated utility in cell-based assays. We used HeLa and Swiss 3T3 cells for these studies because the robust Rac1 activation induced by EGF stimulation in these cells serves as an excellent positive control. ${ }^{46-48}$ Active Racl-GTP levels in lysates of HeLa cells treated with the activator compounds were quantified by capture on GST-PAK-PBD-coated beads, and subsequent analysis by flow cytometry to determine Rac1-GTP levels at various doses of each compound (Figure 5a).
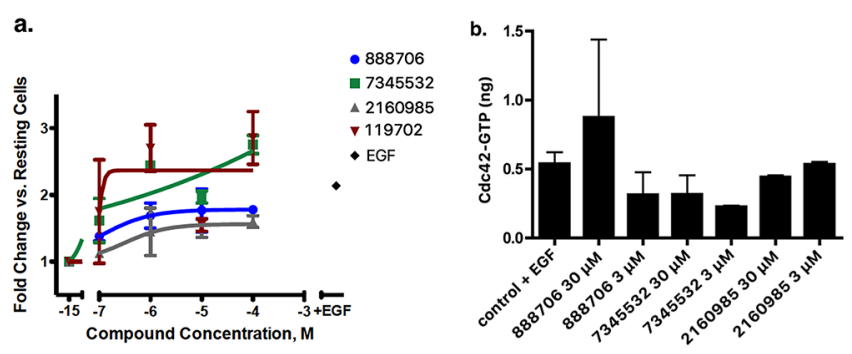

Figure 5. Small molecule activators lead to Rac1 and Cdc42 activation in cell-based assays. (a) Racl activation measured in an effector binding, bead-based flow cytometry assay. HeLa cells were serum starved overnight and then treated with DMSO (basal GTPase activity control - resting), activator compound, or $100 \mathrm{ng} / \mathrm{mL}$ EGF (stimulated positive control) for $2 \mathrm{~min}$. Four activator compounds were tested at four concentrations each in the range of $0.1-100 \mu \mathrm{M}(n$ $=2$ ). Plotted are fold changes in Rac1-GTP levels in cells treated with compounds or EGF relative to those in resting cells. (b) Cdc42 activation measured in a GLISA. Swiss 3T3 cells were serum starved overnight and then treated with the indicated concentrations of the activator compounds. After serum starvation, control cells were treated with DMSO (vehicle) and stimulated with $100 \mathrm{ng} / \mathrm{mL}$ EGF for $2 \mathrm{~min}$. Three lead compounds each were tested at 3 and $30 \mu \mathrm{M}(n=2)$. The baseline level Cdc42-GTP detected in resting cells was set to zero and subtracted from all values.

Treatment with $\geq 1 \mu \mathrm{M}$ doses of all the compounds tested caused an increased level of Racl activation comparable to that of EGF-stimulated positive control samples. Robust Rac1 activation was also observed in Swiss 3T3 cells with either activator 888706 or EGF stimulation (Figure S6). Quantification via GLISAs demonstrated Cdc42 activation in Swiss 3T3 cells at two doses by representative members of each of the three chemical families through PAK binding (Figure 5b). Overall, the lead compounds from all three chemical families of activators caused robust increases in the levels of GTP-bound forms of both Rac1 and Cdc42 GTPases in cell-based assays.

Small Molecule Activators Increase Rho Family GTPase-Modulated Responses in Cell-Based Assays. Inside cells, binding to small molecules might differentially impact downstream GTPase-mediated signaling through effector proteins. Burns et al. reported that small molecules that increased cellular levels of Ras-GTP negatively governed signaling output. ${ }^{49}$ Therefore, after observing increases in Rac1GTP and Cdc42-GTP levels in the cells treated with the small molecule activators, we further investigated effects on downstream Rho family GTPase-modulated cellular responses. The Rho family GTPases play important roles in morphological transformation and migration of cells through governance of actin cytoskeleton rearrangements. While RhoA is most often associated with actin stress fiber regulation, Racl promotes actin polymerization at the leading edge and orchestrates the formation of lamellipodia and membrane ruffles $\mathrm{Cdc} 42$ nucleates peripheral actin microspikes and filopodia. ${ }^{48,50}$ To characterize the morphologic responses to the three activator families, we utilized the rat basophilic leukemia cell line (RBL2H3). RBL-2H3 intracellular signaling, cell ruffling, and spreading responses are readily monitored by ligand-stimulated activation of the $\operatorname{IgE}$ receptor, FceRI, and are known to be highly dependent on Racl and $\mathrm{Cdc} 42.51,52$

RBL-2H3 cells were left untreated, ligand stimulated with dinitrophenyl bovine serum albumin (DNP-BSA), or incubated with $888706(10 \mu \mathrm{M})$. Live cell imaging and fixed cell imaging were used to monitor and quantify cell shape changes, along with actin rearrangements related to ruffling and spreading. Treatment of resting RBL-2H3 cells with 888706 caused a remarkable transformation in cell surface topography and shape, including flattening, an increase in surface area, and formation of lamellipodia and microspikes (Figure S7b). This response was analogous to what is observed when cells are stimulated by cross-linking of FceRI with DNP-BSA ligand and quite distinct from that of DMSO-treated control resting cells $(t=0)$ (Figure S7a,b). Resting RBL-2H3 cells treated with a Rac GTPase inhibitor (781112) showed no change in morphology and completely abrogated normal cell shape changes in response to ligand-mediated activation. ${ }^{53}$ Strikingly, the addition of the inhibitor 781112 to cells prior to or after they had been initially stimulated with 888706 caused cells to sequentially lose their lamellipodia, retract from the substrate, and become progressively more round as they returned to a resting cell morphology within $75 \mathrm{~min}$ of inhibitor addition (Figure S7c). On the basis of the reactive chemical structure of inhibitor 781112, we speculate that it may act as an irreversible inhibitor. The data suggest small molecule-mediated activation is reversible.

Confocal analyses of actin rearrangements, another cell-based measure of Rho family activation, revealed that RBL-2H3 cells treated with six different activators (two from each chemical family), analogous to ligand-stimulated (DNP-BSA) cells, were flattened significantly with the cell height decreasing on average 2 -fold as compared to that of DMSO controls (Figure 6a, $x-z$ view). Cells lost their spherical appearance and became spread and elongated on the substratum, with actin becoming localized to the cell perimeter, leading edge, and protrusions (Figure 6a, $x-y$ view). Thus, cell activation in response to tested GTPase activators occurred rapidly $(0-60 \mathrm{~min})$ and on a time scale similar to that of ligand-stimulated receptor activation.

We capitalized on the sensitivity of RBL-2H3 morphologic changes to monitor cell activation to perform cellular doseresponse assays $(0.03-30 \mu \mathrm{M})$ on two compounds from each of the three chemical families (Figure $6 \mathrm{~b}-\mathrm{g}$ ). Increases in cell area were used to quantify cell flattening in response to GTPase activator treatment; untreated cells and cells treated with $1 \%$ DMSO served as negative controls. DMSO treatment alone caused some cell flattening relative to untreated controls (Figure $6 \mathrm{~b}-\mathrm{g}$ ). Because all compounds were administered in 

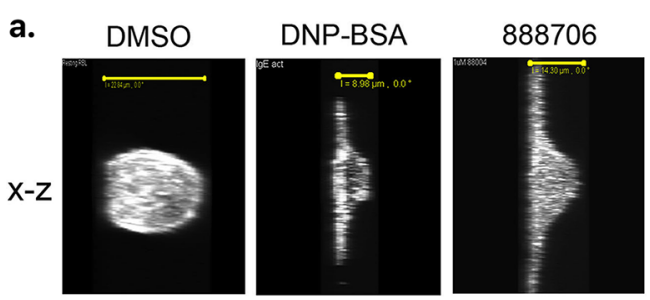

7345532
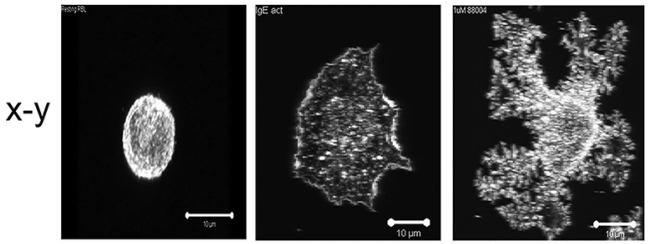

2160985

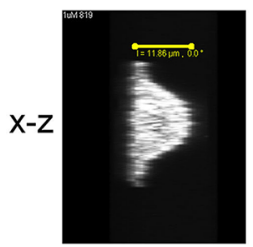

4136409

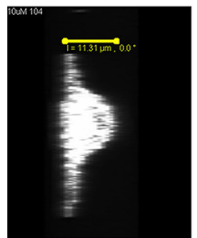

22332897
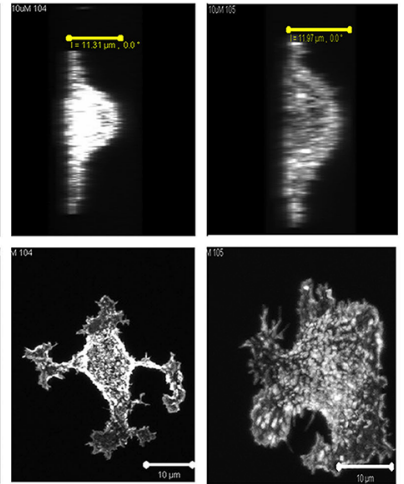
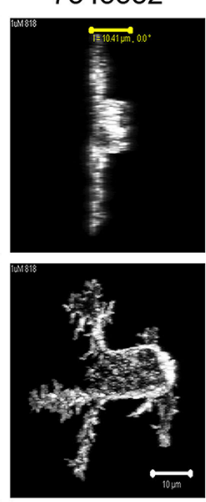

119702
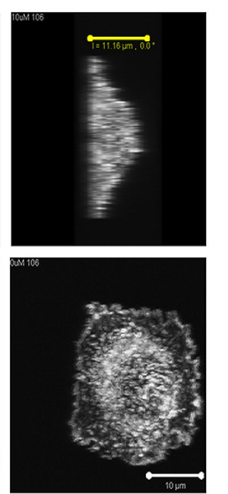

b.

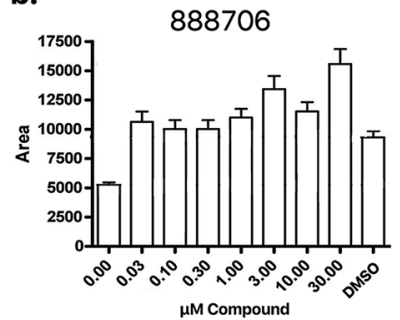

d.

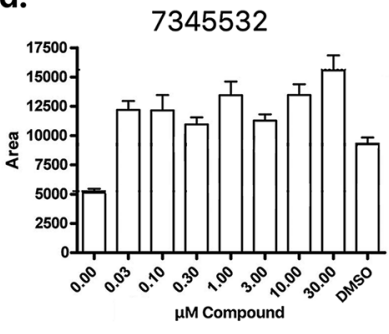

f.

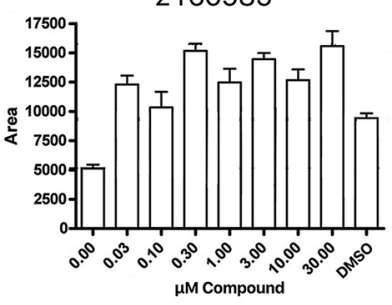

c.

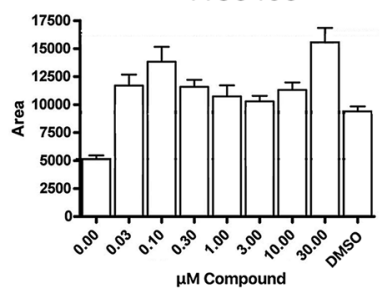

e.

22332897

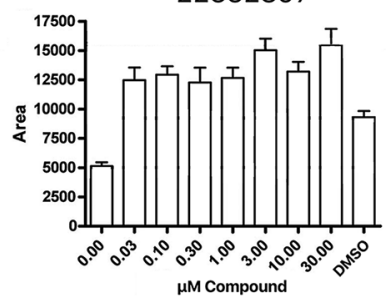

g.

119702

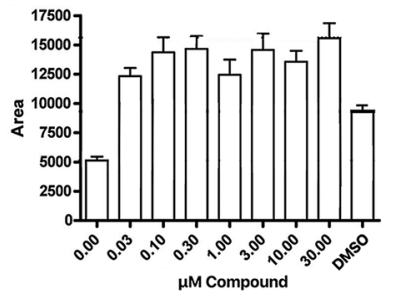

Figure 6. Small molecule activators induce Rho family GTPase-dependent morphologic changes in cells. (a) Resting RBL-2H3 mast cells were treated with DMSO (negative control, $t_{0}$ ), stimulated with ligand (DNP-BSA) to activate (positive control), or treated with two representative compounds $(10 \mu \mathrm{M})$ from each of the three chemical families. Samples were fixed and stained with rhodamine phalloidin to visualize the actin cytoskeleton. Individual panels show $x-y$ and $x-z$ views of representative cells $(n=3)$. Bars are $10 \mu \mathrm{m}$. $(\mathrm{b}-\mathrm{g})$ Cell-based dose-response assays conducted across a dose range of $0.03-30 \mu \mathrm{M}$. Cell activation was quantified as an increase in cell area due to cell flattening. Four micrographs were counted for each condition taken at 40× magnification representing approximately 60-200 cells counted per condition. Untreated and DMSOtreated cells served as negative controls. DNP-BSA-stimulated cells provided a measure of maximal activation $(n=3)$.

$1 \%$ DMSO, this control served as the baseline for monitoring the additional cell response in the presence of the compounds. All six compounds yielded maximal cell flattening at concentrations of $30 \mu \mathrm{M}$ (Figure $6 \mathrm{~b}-\mathrm{g}$ ). The two nicotinic acid compounds had potencies in the range of $10-30 \mu \mathrm{M}$ (Figure 6b,c), while the indole acid (Figure 6d,e) and salicylic acid (Figure 6f,g) compounds activated cells at submicromolar doses $(0.03-0.1 \mu \mathrm{M})$. Taken together, the data demonstrate stimulatory activities on Rac-regulated cell signaling and actin remodeling by representative members of all three GTPase activator families.

To conclude, we have characterized the mechanism of action of representative novel small molecule activators that bind to Ras superfamily GTPases and stabilize the GTP-bound active form both in vitro and under physiologic conditions in cells. We primarily present indirect proof of activator binding. Initial microscale thermophoresis (Figure S10) analyses support direct binding, and the measured $K_{\mathrm{d}}$ of $90 \mathrm{nM}$ for compound 888706 on Cdc42 is in excellent agreement with the $100 \mathrm{nM} \mathrm{IC}_{50}$ value calculated via the flow cytometric data (Figure $2 \mathrm{~b}$ and Table S2). Further studies are underway to investigate how these activators bind to small GTPases. The identified lead compounds provide scaffolds from which more selective activators (exemplified by CIDs 16194519, 3744270, and 3538522 with emerging GTPase selectivity) might be developed. The activators are of particular interest for research and translational studies of inherited and infectious diseases in which diminished GTPase activities cause immune dysfunction, Fanconi anemia, and neurological disorders. ${ }^{20,27,54}$ Importantly, such specific and pan GTPase activators could provide advantages over genetic methodologies in cell-based assays, for measuring the initial and/or acute response of reversibly altering activities of GTPases. Furthermore, these molecules provide a scaffold for structure-based design of agonists against Rho family GTPases to complement existing antagonists or inhibitors. A similar strategy has proven to be extremely effective for studying and therapeutically targeting G-proteincoupled receptors. ${ }^{55}$ As Ras superfamily GTPases gain increasing traction as viable targets for further probe and drug discovery, our studies provide a chemical platform for the rational design of selective activators of key Ras superfamily members that could represent a boon for an improved understanding of the biology and pharmacology of small GTPases.

\section{METHODS}

Effect of Activators on Dbs RhoGEF Activity. GSH beads \{see Figure $\mathrm{S} 1 ; 100 \mu \mathrm{L}$ of beads centrifuged and resuspended in $50 \mu \mathrm{L}$ of NP-HPS buffer [0.01\% NP-40, $30 \mathrm{mM}$ HEPES (pH 7.5), $100 \mathrm{mM}$ $\mathrm{KCl}$, and $20 \mathrm{mM} \mathrm{NaCl}$ ] containing $1 \mathrm{mM}$ EDTA\} were incubated with purified GST-Cdc42 wt $\left(10 \mu \mathrm{L}\right.$ of a $1 \mathrm{mg} \mathrm{mL}^{-1}$ solution) overnight at $4{ }^{\circ} \mathrm{C}$. On the basis of the number of binding sites per bead, a total of $0.03 \mathrm{pmol}$ of $\mathrm{Cdc} 42$ is bound to the beads used in the assay. For nucleotide loading, beads were washed with NP-HPS buffer 
containing $1 \mathrm{mM}$ EDTA, $0.1 \% \mathrm{BSA}$, and $1 \mathrm{mM}$ DTT and resuspended in $100 \mu \mathrm{L}$ of NP-HPE buffer (10 mM EDTA in NP-HPS) for $20 \mathrm{~min}$ at $30^{\circ} \mathrm{C}$. The nucleotide was depleted by sequential washes with NPHPS, after which bead-immobilized Cdc42 was incubated with $10 \mu \mathrm{Ci}$ of $\left[{ }^{3} \mathrm{H}\right] \mathrm{GDP}$ and $1 \mu \mathrm{M}$ GDP in the presence of $1 \mathrm{mM}$ EDTA (in NPHPS buffer) for $20 \mathrm{~min}$ at $30{ }^{\circ} \mathrm{C}$. To prevent the dissociation of the tritiated guanine nucleotide from $\mathrm{Cdc} 42, \mathrm{MgCl}_{2}$ was added until a final concentration of $20 \mathrm{mM}$ was reached.

The ability of the activator compounds to promote nucleotide exchange and their impact on GEF activity were tested by measuring dissociation of $\left[{ }^{3} \mathrm{H}\right] \mathrm{GDP}$ from $\mathrm{Cdc} 42$ over time with or without GEF protein present. To test whether activator compound binding promotes nucleotide exchange (Figure 4a), the following assay was used. DMSO alone, $10 \mu \mathrm{M}$ activator compounds (10 min preincubation at room temperature before the addition of GTP), or $200 \mathrm{nM}$ His-DBS was added to aliquots of bead-immobilized Cdc42 preloaded with $\left[{ }^{3} \mathrm{H}\right] \mathrm{GDP}$. The $\mathrm{Cdc} 42$ concentration in the final assay volume was $\sim 0.04 \mathrm{nM}$. The GDP/GTP exchange reaction was conducted in GEF buffer (NP-HPS with $1 \mathrm{mM}$ EDTA, $5 \mathrm{mM} \mathrm{MgCl}_{2}$, $0.1 \% \mathrm{BSA}$, and $1 \mathrm{mM}$ DTT). The initial $\left[{ }^{3} \mathrm{H}\right]$ GDP-Cdc42-bound radioactivity was measured prior to addition of unlabeled GTP, while exchange was initiated with the addition of $250 \mu \mathrm{M}$ GTP (final concentration). The reactions were stopped when the mixtures were transferred to ice at indicated time points $(0-30 \mathrm{~min})$, and the amount of $\left[{ }^{3} \mathrm{H}\right] \mathrm{GDP}$ remaining bound to the $\mathrm{Cdc} 42$ beads was measured. To determine whether the GTPase-bound, small molecule activators have an impact on GEF activity, we tested nucleotide exchange in the presence of the compounds and GEF (Figure 4b). $\left[{ }^{3} \mathrm{H}\right] \mathrm{GDP}$ was loaded onto bead-immobilized Cdc42. Beads were washed and resuspended in GEF buffer, and $100 \mu \mathrm{L}$ aliquots were preincubated with $1 \%$ DMSO alone or $10 \mu \mathrm{M}$ compound in $1 \%$ DMSO for $10 \mathrm{~min}$ at room temperature to allow compound binding. Subsequently, $200 \mathrm{nM}$ His-DBS (DH/PH domain) was added. The GDP/GTP exchange reaction was initiated with the addition of 250 $\mu \mathrm{M}$ GTP (final concentration), and reactions were stopped when the samples were transferred to ice after a $20 \mathrm{~min}$ incubation at $30{ }^{\circ} \mathrm{C}$. Following termination of both assays, bead-bound $\mathrm{Cdc} 42$ was collected by centrifugation and washed twice with ice-cold GEF buffer, and the remaining radioactivity was measured. The beadassociated radioactivity was measured by scintillation counting. A single-phase exponential decay model was used to fit the nucleotide exchange data in the presence of the $\mathrm{Dbs}$ GEF. A two-phase exponential decay model was used to fit the data as a combination of fast and slow exponential decays for the compounds. The equation used is $Y=S_{1} \mathrm{e}^{-K_{1} t}+S_{2} \mathrm{e}^{-K_{2} t}$, where $S_{1}+S_{2}=100$. The Gauss-Newton algorithm was used to estimate the parameters by minimizing the sum of squares of errors between the data and model predictions. The analyses were performed using statistical software $\mathrm{R}$ version 3.4.4.

GAP Assay. RhoGAP activity on RhoA and Racl GTPases was measured using purified proteins in the presence and absence of compounds using the assay from Cytoskeleton, Inc. (catalog no. BK105), per the manufacturer's instructions. Compounds were preincubated with the GTPase $(17.8 \mu \mathrm{M})$ for $15 \mathrm{~min}$ prior to the addition of RhoGAP $(5.5 \mu \mathrm{M})$. Phosphate release was measured colorimetrically and read on a SpectraMax plate reader at $650 \mathrm{~nm}$ (Molecular Devices, Sunnyvale, CA). A phosphate standard curve was used to calculate GTPase activity (nanomoles of $\mathrm{P}_{\mathrm{i}}$ per minute per milligram).

Cell Dose-Response Measurements Based on Cell Shape Changes. RBL-2H3 cells were left untreated or treated with DMSO [negative controls, treated with $1 \mathrm{mg} \mathrm{mL}^{-1} \mathrm{DNP} / \mathrm{BSA}$ (positive control)] or incubated in the presence of $0.03-10 \mu \mathrm{M}$ compound. Cells were fixed and processed for immunofluorescence and stained with rhodamine phalloidin to visualize actin, antibodies against Pak or Rac, and Hoechst to label nuclei. Three images were taken at 40X magnification of each condition using a Zeiss Axioskop instrument fitted with an Axiocam digital camera. Digital images were imported into MATLAB for assessment of cell area and perimeter (Figure S8). The following steps were performed to obtain a quantitative estimate of the two cell parameters for RGB to gray transformation of images followed by transformation to black and white images using an automatically computed threshold. In the black and white images, the boundaries were detected automatically by differentiating between zero pixels for the background and non-zero pixels for the objects. With delimited boundaries, the area and perimeter were computed by counting the pixels for each object.

\section{ASSOCIATED CONTENT}

\section{Supporting Information}

The Supporting Information is available free of charge on the ACS Publications website at DOI: 10.1021/acschembio. 8 b00038.

Supplementary Methods; reagents and cell lines, mass spectrometry confirmation of purchased compounds, multiplexed primary screens and statistical analyses, virtual screening and structural analysis, dose-response measurements and selection criteria for active compounds, Rac1 activation assays, live cell microscopy, immunofluorescence staining and microscopy, SAR for three chemical families of GTPase activators, and statistical analyses (Figures $S 1-S 10$, respectively); and Tables S1-S4 (PDF)

\section{AUTHOR INFORMATION}

\section{Corresponding Author}

*Department of Pathology, MSC 08 4640, University of New Mexico HSC, Albuquerque, NM 87131. Phone: 505-272-1459. Fax: 505-272-5186.

ORCID ${ }^{\circ}$

Charuta C. Palsuledesai: 0000-0002-3850-260X

\section{Present Addresses}

OT.F.M.: Sapienza University of Rome, Rome, Italy.

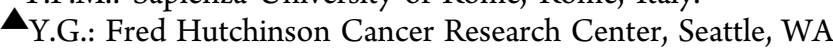
98109-1024.

$\triangle$ Y.W.: Intellectual Venture Laboratories, Bellevue, WA 98007.

J.S.: Centerra Gold, Inc., Mount Milligan, BC, Canada.

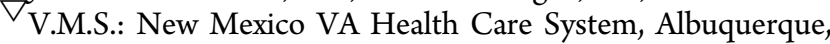
NM 87108.

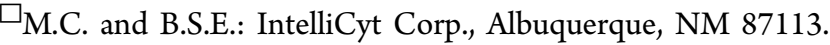
Author Contributions

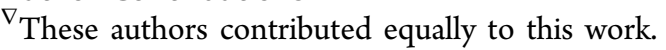

Author Contributions

- These authors contributed equally to this work.

Author Contributions

HTS screening and secondary dose-response measurements were performed by Z.S., Y.W., S.Y., M.C., T.F., and B.S.E. Kinetic binding experiments were performed by Z.S., H.A., and M.K.H. Bioinformatics, cheminformatics, and statistical analyses were performed by T.F.M., O.N., A.W., V.M.S., O.U., R.C., B.S.E., C.G.B., T.I.O., Z.G., and L.L. Cell-based assays of GTPase activation and morphologic changes were performed by Z.S. and Y.G. Chemical libraries, compound management, virtual screening, and docking studies were performed by J.S., O.U., C.G.B., and T.I.O. Data interpretation, manuscript writing, and figure preparation were performed by C.C.P., A.W., Z.S., Y.G., O.U., C.G.B., T.I.O., A.W.-N., and L.A.S.

Notes

The authors declare no competing financial interest.

Retired.

Deceased.

$\diamond_{\text {Retired. }}$ 


\section{ACKNOWLEDGMENTS}

This work was generously supported by National Science Foundation Grant MCB0446179 and National Institutes of Health (NIH) Grant R03 MH081231 to A.W.-N.; NIH Grants CA118100, U54 MH074425, and U54 MH084690 to L.A.S.; National Cancer Institute (NCI) Grant R25CA153825 (predoctoral fellowship) and the G. D. Montoya Scholarship to Y.G.; and National Institute of General Medical Sciences (NIGMS) Postdoctoral Fellowship P50 GM085273 to C.C.P. Small molecule high-throughput screening was performed in the New Mexico Molecular Libraries Screening Center. Followup flow cytometry assays and microscopic imaging were conducted in the University of New Mexico Comprehensive Cancer Center Flow Cytometry, Biostatistics, and Fluorescence Microscopy Shared Resources (supported by NCI Grant P30 CA118100 and NIGMS Grant 5P50 GM085273). The authors gratefully acknowledge A. Kornienko for synthesis of EHT1864 and G. Bokoch for GST-PAK-PBD beads. We thank Dr. Lin Hong the execution of the microscale thermophoresis studies. RBL-2H3 cells were from B. Wilson. T.F.M. and O.N. thank Università di Bari “Aldo Moro” for funding.

\section{DEDICATION}

This work is dedicated to the memories of Dr. Gary Bokoch and Susan Young, MS.

\section{REFERENCES}

(1) Takai, Y., Sasaki, T., and Matozaki, T. (2001) Small GTP-binding proteins. Physiol. Rev. 81, 153-208.

(2) Wennerberg, K., Rossman, K. L., and Der, C. J. (2005) The Ras superfamily at a glance. J. Cell Sci. 118, 843-846.

(3) Hong, L., and Sklar, L. A. (2014) Targeting GTPases in Parkinson's disease: comparison to the historic path of kinase drug discovery and perspectives. Front. Mol. Neurosci. 7, 52.

(4) Braun, B. S., and Shannon, K. (2008) Targeting Ras in myeloid leukemias. Clin. Cancer Res. 14, 2249-2252.

(5) Ellenbroek, S. I. J., and Collard, J. G. (2007) Rho GTPases: functions and association with cancer. Clin. Exp. Metastasis 24, 657672.

(6) Hong, L., Guo, Y., BasuRay, S., Agola, J. O., Romero, E., Simpson, D. S., Schroeder, C. E., Simons, P., Waller, A., Garcia, M., Carter, M., Ursu, O., Gouveia, K., Golden, J. E., Aube, J., Wandinger-Ness, A., and Sklar, L. A. (2015) A Pan-GTPase Inhibitor as a Molecular Probe. PLoS One 10, e0134317.

(7) Johnson, J. L., Ramadass, M., He, J., Brown, S. J., Zhang, J., Abgaryan, L., Biris, N., Gavathiotis, E., Rosen, H., and Catz, S. D. (2016) Identification of neutrophil exocytosis inhibitors (Nexinhibs), small molecule inhibitors of neutrophil exocytosis and inflammation: Druggability of the small GTPase Rab27a. J. Biol. Chem. 291, 2596525982.

(8) Guo, Y., Kenney, S. R., Muller, C. Y., Adams, S., Rutledge, T., Romero, E., Murray-Krezan, C., Prekeris, R., Sklar, L. A., Hudson, L. G., and Wandinger-Ness, A. (2015) R-Ketorolac Targets Cdc42 and Rac1 and Alters Ovarian Cancer Cell Behaviors Critical for Invasion and Metastasis. Mol. Cancer Ther. 14, 2215-2227.

(9) Ostrem, J. M., and Shokat, K. M. (2016) Direct small-molecule inhibitors of KRAS: from structural insights to mechanism-based design. Nat. Rev. Drug Discovery 15, 771-785.

(10) Nassar, N., Cancelas, J., Zheng, J., Williams, D. A., and Zheng, Y. (2006) Structure-function based design of small molecule inhibitors targeting Rho family GTPases. Curr. Top. Med. Chem. 6, 1109-1116.

(11) Brumell, J. H., and Scidmore, M. A. (2007) Manipulation of Rab GTPase function by intracellular bacterial pathogens. Microbiol. Mol. Biol. Rev. 71, 636
(12) Banworth, M. J., and Li, G. (2018) Consequences of Rab GTPase Dysfunction in Genetic or Acquired Human Diseases. Small GTPases 9, 158.

(13) Buday, L., and Downward, J. (2008) Many faces of Ras activation. Biochim. Biophys. Acta, Rev. Cancer 1786, 178-187.

(14) Simanshu, D. K., Nissley, D. V., and McCormick, F. (2017) RAS Proteins and Their Regulators in Human Disease. Cell 170, 17-33.

(15) Yan, C., and Theodorescu, D. (2018) RAL GTPases: Biology and Potential as Therapeutic Targets in Cancer. Pharmacol. Rev. 70, $1-11$.

(16) Khosravi-Far, R., Chrzanowskawodnicka, M., Solski, P. A., Eva, A., Burridge, K., and Der, C. J. (1994) Dbl and Vav Mediate Transformation Via Mitogen-Activated Protein-Kinase Pathways That Are Distinct from Those Activated by Oncogenic Ras. Mol. Cell. Biol. $14,6848-6857$.

(17) Patel, V., Rosenfeldt, H. M., Lyons, R., Servitja, J. M., Bustelo, X. R., Siroff, M., and Gutkind, J. S. (2007) Persistent activation of Racl in squamous carcinomas of the head and neck: evidence for an EGFR/ Vav2 signaling axis involved in cell invasion. Carcinogenesis 28, 11451152.

(18) Jaffe, A. B., and Hall, A. (2005) Rho GTPases: biochemistry and biology. Annu. Rev. Cell Dev. Biol. 21, 247-269.

(19) Schwartz, S. L., Cao, C., Pylypenko, O., Rak, A., and WandingerNess, A. (2007) Rab GTPases at a glance. J. Cell Sci. 120, 3905-3910.

(20) Cheng, K. W., Lahad, J. P., Gray, J. W., and Mills, G. B. (2005) Emerging role of RAB GTPases in cancer and human disease. Cancer Res. 65, 2516-2519.

(21) Nachury, M. V., Loktev, A. V., Zhang, Q., Westlake, C. J., Peranen, J., Merdes, A., Slusarski, D. C., Scheller, R. H., Bazan, J. F., Sheffield, V. C., and Jackson, P. K. (2007) A core complex of BBS proteins cooperates with the GTPase Rab8 to promote ciliary membrane biogenesis. Cell 129, 1201-1213.

(22) Wandinger-Ness, A., and Zerial, M. (2014) Rab proteins and the compartmentalization of the endosomal system. Cold Spring Harbor Perspect. Biol. 6, a022616.

(23) Agola, J. O., Jim, P. A., Ward, H. H., Basuray, S., and WandingerNess, A. (2011) Rab GTPases as regulators of endocytosis, targets of disease and therapeutic opportunities. Clin. Genet. 80, 305-318.

(24) Dang, C. V., Reddy, E. P., Shokat, K. M., and Soucek, L. (2017) Drugging the 'undruggable' cancer targets. Nat. Rev. Cancer 17, 502508.

(25) Papke, B., and Der, C. J. (2017) Drugging RAS: Know the enemy. Science 355, 1158-1163.

(26) Gu, Y., Jia, B., Yang, F. C., D'Souza, M., Harris, C. E., Derrow, C. W., Zheng, Y., and Williams, D. A. (2001) Biochemical and biological characterization of a human Rac2 GTPase mutant associated with phagocytic immunodeficiency. J. Biol. Chem. 276, 15929-15938.

(27) Zhang, X. L., Shang, X., Guo, F. K., Murphy, K., Kirby, M., Kelly, P., Reeves, L., Smith, F. O., Williams, D. A., Zheng, Y., and Pang, Q. S. (2008) Defective homing is associated with altered Cdc42 activity in cells from patients with Fanconi anemia group A. Blood 112, 16831686.

(28) Bhuin, T., and Roy, J. K. (2014) Rab proteins: the key regulators of intracellular vesicle transport. Exp. Cell Res. 328, 1-19.

(29) Goitre, L., Trapani, E., Trabalzini, L., and Retta, S. F. (2014) The Ras superfamily of small GTPases: the unlocked secrets. Methods Mol. Biol. 1120, 1-18.

(30) Mrozowska, P. S., and Fukuda, M. (2016) Regulation of podocalyxin trafficking by Rab small GTPases in $2 \mathrm{D}$ and $3 \mathrm{D}$ epithelial cell cultures. J. Cell Biol. 213, 355-369.

(31) Yau, E. H., Kummetha, I. R., Lichinchi, G., Tang, R., Zhang, Y., and Rana, T. M. (2017) Genome-Wide CRISPR Screen for Essential Cell Growth Mediators in Mutant KRAS Colorectal Cancers. Cancer Res. 77, 6330-6339.

(32) Maresch, R., Mueller, S., Veltkamp, C., Ollinger, R., Friedrich, M., Heid, I., Steiger, K., Weber, J., Engleitner, T., Barenboim, M., Klein, S., Louzada, S., Banerjee, R., Strong, A., Stauber, T., Gross, N., Geumann, U., Lange, S., Ringelhan, M., Varela, I., Unger, K., Yang, F., Schmid, R. M., Vassiliou, G. S., Braren, R., Schneider, G., 
Heikenwalder, M., Bradley, A., Saur, D., and Rad, R. (2016) Multiplexed pancreatic genome engineering and cancer induction by transfection-based CRISPR/Cas9 delivery in mice. Nat. Commun. 7, 10770.

(33) Kawasumi, M., and Nghiem, P. (2007) Chemical genetics: elucidating biological systems with small-molecule compounds. J. Invest. Dermatol. 127, 1577-1584.

(34) Weiss, W. A., Taylor, S. S., and Shokat, K. M. (2007) Recognizing and exploiting differences between RNAi and smallmolecule inhibitors. Nat. Chem. Biol. 3, 739-744.

(35) El-Brolosy, M. A., and Stainier, D. Y. R. (2017) Genetic compensation: A phenomenon in search of mechanisms. PLoS Genet. 13, e1006780.

(36) Castoreno, A. B., and Eggert, U. S. (2011) Small molecule probes of cellular pathways and networks. ACS Chem. Biol. 6, 86-94.

(37) DeRose, R., Pohlmeyer, C., Umeda, N., Ueno, T., Nagano, T., Kuo, S., and Inoue, T. (2012) Spatio-temporal manipulation of small GTPase activity at subcellular level and on timescale of seconds in living cells. J. Visualized Exp., 3794.

(38) Rose, J. C., Huang, P. S., Camp, N. D., Ye, J., Leidal, A. M., Goreshnik, I., Trevillian, B. M., Dickinson, M. S., Cunningham-Bryant, D., Debnath, J., Baker, D., Wolf-Yadlin, A., and Maly, D. J. (2017) A computationally engineered RAS rheostat reveals RAS-ERK signaling dynamics. Nat. Chem. Biol. 13, 119-126.

(39) Surviladze, Z., Ursu, O., Miscioscia, F., Curpan, R., Halip, L., Bologa, C., Oprea, T., Waller, A., Strouse, J., Salas, V., Wu, Y., Edwards, B., Wandinger-Ness, A., and Sklar, L. (2010) Three small molecule pan activator families of Ras-related GTPases. In Probe Reports from the NIH Molecular Libraries Program, National Institutes of Health, Bethesda, MD.

(40) Kuckuck, F. W., Edwards, B. S., and Sklar, L. A. (2001) High throughput flow cytometry. Cytometry 44, 83-90.

(41) Willett, P. (2005) Searching techniques for databases of twoand three-dimensional chemical structures. J. Med. Chem. 48, 41834199.

(42) Hristozov, D. P., Oprea, T. I., and Gasteiger, J. (2007) Virtual screening applications: a study of ligand-based methods and different structure representations in four different scenarios. J. Comput.-Aided Mol. Des. 21, 617-640.

(43) Oprea, T. I., Sklar, L. A., Agola, J. O., Guo, Y., Silberberg, M., Roxby, J., Vestling, A., Romero, E., Surviladze, Z., Murray-Krezan, C., Waller, A., Ursu, O., Hudson, L. G., and Wandinger-Ness, A. (2015) Novel activities of select NSAID R-enantiomers against Racl and Cdc42 GTPases. PLoS One 10, e0142182.

(44) Guo, Z., Ahmadian, M. R., and Goody, R. S. (2005) Guanine nucleotide exchange factors operate by a simple allosteric competitive mechanism. Biochemistry 44, 15423-15429.

(45) Thompson, G., Owen, D., Chalk, P. A., and Lowe, P. N. (1998) Delineation of the Cdc42/Rac-binding domain of p21-activated kinase. Biochemistry 37, 7885-7891.

(46) Samson, T., Welch, C., Monaghan-Benson, E., Hahn, K. M., and Burridge, K. (2010) Endogenous RhoG is rapidly activated after epidermal growth factor stimulation through multiple guaninenucleotide exchange factors. Mol. Biol. Cell 21, 1629-1642.

(47) Buranda, T., BasuRay, S., Swanson, S., Agola, J., Bondu, V., and Wandinger-Ness, A. (2013) Rapid parallel flow cytometry assays of active GTPases using effector beads. Anal. Biochem. 442, 149-157.

(48) Ridley, A. J., Paterson, H. F., Johnston, C. L., Diekmann, D., and Hall, A. (1992) The small GTP-binding protein rac regulates growth factor-induced membrane ruffling. Cell 70, 401-410.

(49) Burns, M. C., Sun, Q., Daniels, R. N., Camper, D., Kennedy, J. P., Phan, J., Olejniczak, E. T., Lee, T., Waterson, A. G., Rossanese, O. W., and Fesik, S. W. (2014) Approach for targeting Ras with small molecules that activate SOS-mediated nucleotide exchange. Proc. Natl. Acad. Sci. U. S. A. 111, 3401-3406.

(50) Nobes, C. D., and Hall, A. (1995) Rho, rac, and cdc42 GTPases regulate the assembly of multimolecular focal complexes associated with actin stress fibers, lamellipodia, and filopodia. Cell 81, 53-62.
(51) Guillemot, J. C., Montcourrier, P., Vivier, E., Davoust, J., and Chavrier, P. (1997) Selective control of membrane ruffling and actin plaque assembly by the Rho GTPases Racl and CDC42 in FcepsilonRI-activated rat basophilic leukemia (RBL-2H3) cells. J. Cell Sci. 110 (Part 18), 2215-2225.

(52) Djouder, N., Prepens, U., Aktories, K., and Cavalie, A. (2000) Inhibition of calcium release-activated calcium current by $\mathrm{Rac} / \mathrm{Cdc} 42-$ inactivating clostridial cytotoxins in RBL cells. J. Biol. Chem. 275, $18732-18738$.

(53) Surviladze, Z., Waller, A., Wu, Y., Romero, E., Edwards, B. S. Wandinger-Ness, A., and Sklar, L. A. (2010) Identification of a Small GTPase Inhibitor Using a High-Throughput Flow Cytometry BeadBased Multiplex Assay. J. Biomol. Screening 15, 10-20.

(54) Williams, D. A., Tao, W., Yang, F. C., Kim, C., Gu, Y., Mansfield, P., Levine, J. E., Petryniak, B., Derrow, C. W., Harris, C., Jia, B. Q., Zheng, Y., Ambruso, D. R., Lowe, J. B., Atkinson, S. J., Dinauer, M. C., and Boxer, L. (2000) Dominant negative mutation of the hematopoietic-specific Rho GTPase, Rac2, is associated with a human phagocyte immunodeficiency. Blood 96, 1646-1654.

(55) Dennis, M. K., Field, A. S., Burai, R., Ramesh, C., Petrie, W. K., Bologa, C. G., Oprea, T. I., Yamaguchi, Y., Hayashi, S., Sklar, L. A., Hathaway, H. J., Arterburn, J. B., and Prossnitz, E. R. (2011) Identification of a GPER/GPR30 antagonist with improved estrogen receptor counterselectivity. J. Steroid Biochem. Mol. Biol. 127, 358-366. 